Original Article

\title{
SYNERGISTIC CYTOTOXIC EFFECT OF STATINS AND BISPHOSPHONATES ON SQUAMOUS CELL CARCINOMA CELL LINE
}

\author{
DINA SABRY ABD-EL-FATTAH ${ }^{1}$, MARWA MOHAMMED ELLITHY'2, RIHAM MOHAMMED ALY ${ }^{3}$ \\ ${ }^{1}$ Professor of Biochemistry, Faculty of Medicine, Cairo University, ${ }^{2}$ Researcher of Oral Pathology, Basic Dental Sciences Department, \\ National Research Centre, ${ }^{3}$ Researcher of Oral Biology, Basic Dental Sciences Department, National Research Centre \\ Email: moonlight20_7@yahoo.com
}

Received: 26 Apr 2017 Revised and Accepted: 19 Jun 2017

\begin{abstract}
Objective: The present study aimed at evaluating the in vitro cytotoxic effect of simvastatin (sv) and alendronate (aln) on squamous cell carcinoma cell line (Hep-2 cells).

Methods: Hep-2 cells were divided into four groups; Control group where cells were cultured in the routine culture medium. Alendronate Group (A) consisting of cells cultured in aln in its IC 50. Simvastatin Group(S) cultured in sv in its IC 50. And finally, a combined group (A+S) comprising cells cultured in combined IC 50 dose of sv and aln. To assess the effect of these drugs on Hep-2 cells, cell viability was measured in addition to measuring vascular endothelial growth factor (VEGF) expression by Elisa.

Results: In all groups, a decrease in the mean viability percentages of the treated Hep-2 cells in relation to control cells was observed in all groups. The combination of both agents exhibited a significant (P-values $<0.05)$ synergistic effect on decreasing cell viability and angiogenesis of Hep- 2 cells in vitro. VEGF measures in all groups were significantly lower than the control group (P-values $<0.05$ ). The combination of both drugs at their IC 50 doses can lower the VEGF production by Hep-2 cancer cells (P-values $<0.05$ ).
\end{abstract}

Conclusion: A combination of sv and aln in their Ic50 doses has a dramatic effect on lowering the proliferation and VEGF expression in Hep-2 cancer cells cultured in vitro.

Keywords: Cancer, Chemotherapy, Mevalonate pathway, Statins, Bisphosphonates, Angiogenesis, Cell viability, Cytotoxicity

(C) 2017 The Authors. Published by Innovare Academic Sciences Pvt Ltd. This is an open access article under the CC BY license (http://creativecommons.org/licenses/by/4.0/) DOI: http://dx.doi.org/10.22159/ijpps.2017v9i8.19436

\section{INTRODUCTION}

Cancer is a disease characterised by high mortality and morbidity rates that persistently represents a threat to human life [1]. It is estimated to cause about 7.6 million deaths per year, with $64 \%$ of these cases in developing countries [2,3].

Cancer is considered a multistep disease which involves many changes in cell physiology leading to malignant tumours. Of these changes, is the abnormal cellular growth, i.e. uncontrolled proliferation, and is considered the main biological endpoint of the disease [4]. Tumor cells invasion of adjacent tissues and distant organs, however, are the main cause of morbidity and mortality for nearly all cancer patients [4].

Nevertheless, cancer therapy is still one of the fields where medicine needs much improvement in order to achieve higher efficacy and lower side effects. In conjunction with surgery and radiotherapy, antineoplastic chemotherapy is a standard regimen that is used in the treatment of squamous cell carcinoma of the head and neck (HNSCC) [1]. In addition to chemotherapeutic agents, which are routinely used in cancer treatment protocols, other pharmaceutical compounds are constantly being under trials to face cancer and also to overcome the deleterious side effects of chemotherapy on normal cells neighbouring cancer [5].

Simvastatin, one of the statins, has a potent antitumor activity in vitro [5] and was shown to possess in vivo anti tumor activity in some preclinical models $[6,7]$. Statins work by increasing the effectiveness of anti-cancer drugs, decreasing the resistance of cancer cells and protecting normal cells from the side effects of anticancer agents. Statins family is the most famous HMG-COA reductase inhibitors used in the treatment of hypercholesterolemia. These drugs act by depleting the cellular pool of isoprene precursors so in addition to lowering chlesterol levels they also play pleiotropic biological effects by inhibiting small cell regulating proteins GTPases as Ras and Ras homologous (Rho). Drug induced interference with the mevalonate pathway will alter the Ras/Rho regulated signalling pathways that allow tumor formation and affects the efficacy of anticancer therapeutic drugs [5]

On the other hand, the N-containing bisphosphonates (NBP) family which includes Alendronate, Zolendronic Acid, Pamidronate and Ibandronate decrease the prenylation of Ras and Rho GTPases and down regulates the protein kinases ERK and AKT/PKB. Also, they increase the levels of p21 and p27 proteins [8].

Preclinical studies suggest that BPs may also reduce tumor cell proliferation and viability and increase cellular apoptosis. They also play a role in increasing the efficacy of many anti-neoplastic therapies by inhibiting tumor cell angiogenesis. They also possess an immunomodulatory effect and can decrease tumor cell adhesion and invasion. In conclusion, bisphosphonates are considered by many researchers as antiproliferative, pro-apoptotic, anti-angiogenic (decrease VEGF and PDGF) [12-19].

Our objective in this research was to evaluate the potential of combining cancer therapy with Simvastatin and Alendronate for the treatment of oral squamous cell carcinoma. This was achieved through evaluating the in vitro cytotoxic effect of combining both drugs on Hep-2 cell line and also to test the effect of this combination on angiogenesis of cancer cells.

\section{MATERIALS AND METHODS}

\section{Chemicals and reagents}

-Alendronate (4-amino-1-hydroxy butylidene-1, 1-bisphosphonate) (ALN) preparation:

Stock solutions of the compounds (10 or $20 \mathrm{~mol}$ ) were prepared in distilled water ( $\mathrm{pH}$ adjusted to 7.4 ) and filter-sterilized using a 0.2 $\mu \mathrm{m}$ filter. 
-Simvastatin preparation (Sv):

Stock solutions of the compound were prepared by dissolving the powder in DMSO (dimethyl sulfoxide) not exceeding $0.1 \%$.

-Squamous cell carcinoma cell line (Hep-2) was purchased from Cell Culture Department-VACSERA-EGYPT

-DMEM-medium, penicillin, streptomycin were purchased from Life Technologies, USA.

-The MTT Reagent and Detergent Solution were obtained from

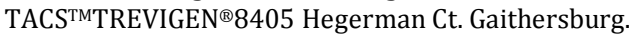

-Human VEGF Elisa kit (Wuhan Huamei Biotech Co., Ltd, Donghu, China)

\section{Preparation of alendronate and simvastatin}

For the preparation of Alendronate (4-amino-1-hydroxy butylidene1, 1-bisphosphonate) (ALN) preparation stock solutions of the compounds (10 or $20 \mathrm{mmol}$ ) were prepared in distilled water $(\mathrm{pH}$ adjusted to 7.4) and filter-sterilized using a $0.2 \mu \mathrm{m}$ filter. As for Simvastatin preparation (Sv), stock solutions of the compound were prepared by dissolving the powder in dimethyl sulfoxide (DMSO) not exceeding $0.1 \%$ (alendronate and simvastatin were purchased from Sigma-Aldrich).

\section{Calculation of IC50 of Aln and Sv}

Squamous cell carcinoma cells (Hep-2) were seeded in 96-well $\mu$ titer plates at an initial concentration of $3 \times 10^{3}$ cell/well in a $150 \mu \mathrm{l}$ fresh medium and left for $24 \mathrm{~h}$ to attach to the plates (Squamous cell carcinoma cell line (Hep-2) was purchased from Cell Culture Department-VACSERA-EGYPT). Different concentrations of drug were added. For each drug concentration, 3 wells were used. The plates were incubated for $48 \mathrm{~h}$. The cells were fixed with $50 \mu \mathrm{l}$ cold trichloroacetic acid $10 \%$ final concentration for 1 hour at $4{ }^{\circ} \mathrm{C}$. The plates were washed with distilled water using the automatic washer (Tecan, Germany) and stained with $50 \mu \mathrm{l} 0.4 \%$ SRB dissolved in $1 \%$ acetic acid for $30 \mathrm{~min}$ at room temperature. The plates were washed with $1 \%$ acetic acid and air-dried. The dye was solubilized with 100 $\mu \mathrm{l} /$ well of $10 \mathrm{Mol}$ tris base $(\mathrm{pH} 10.5)$ and optical density (O. D.) of each well was measured spectrophotometrically at $570 \mathrm{~nm}$ with an Elisa microplate reader (Sunrise Tecan reader, Germany). The mean background absorbance was automatically subtracted and means values of each drug concentration was calculated. The experiment was repeated 3 times. IC50 was defined as the concentration of drug that inhibited cell growth by $50 \%$ (PRISM, GraphPad Software Inc., San Diego, CA, USA). The percentage of cell survival was calculated as follows, Surviving fraction $=0$. D. (treated cells)/O. D. (control cells). The IC50 values (the concentrations of Aln and Sv required to produce $50 \%$ inhibition of cell growth) were calculated.

\section{Cell line and cell culture}

Cells were grown in DMEM-medium $(4,500 \mathrm{mg} / \mathrm{ml}$ of glucose, gluta MAX and sodium pyruvate) supplemented with $10 \%$ fetal calf serum (FCS), $50 \mathrm{U} / \mathrm{ml}$ penicillin and $50 \mathrm{Ig} / \mathrm{ml}$ streptomycin, at $37{ }^{\circ} \mathrm{C}$ in a $5 \% \mathrm{CO}_{2}$ humidified atmosphere. Hep-2 cells were then divided into four groups, Control group cultured in routine culture medium, Group (A) cultured in Aln in its IC 50, Group (S) cultured in Sv in its IC 50 and finally, Group $(A+S)$ cultured in combined IC 50 dose of Sv and Aln.

\section{Cell viability experiments}

The MTT Reagent was added (10 $\mu \mathrm{l}$ per well) and the plate was incubated for 2 to $4 \mathrm{~h}$ to allow for intracellular reduction of the soluble yellow MTT to the insoluble purple formazan dye. When the purple precipitate was clearly visible under the microscope, the detergent reagent was added $(100 \mu \mathrm{l}$ per well) to solubilize the formazan dye. The quantity of formazan product as measured by the amount of $490 \mathrm{~nm}$ absorbance is directly proportional to the number of living cells in culture Plates were left with the cover in the dark for 2 to $4 \mathrm{~h}$ or overnight at room temperature. The plate cover was removed and the absorbance in each well was measured at a range from 490 to $630 \mathrm{~nm}$ in a microplate reader. The optical density (O. D) values were measured at a range from 490 to $630 \mathrm{~nm}$ using an enzyme-linked immunosorbent assay plate reader (Dynatech MRX 5000; Dynex, Chantilly, VA).

\section{Elisa for VEGF}

VEGF was assessed to evaluate the ability of cancer cells for angiogenesis (pg/ml). Human VEGF Elisa kit was used according to manual instructions. The supernatant of the cultured cell was collected in each group to measure VEGF presence using Elisa reader.

\section{Statistical analysis}

Data were coded and entered using the statistical package SPSS version 21. Data were summarised using mean \pm standard deviation for quantitative variables. Comparisons between groups were done using analysis of variance (ANOVA). P-values less than 0.05 were considered as statistically significant.

\section{RESULTS}

\section{IC50 calculation results}

IC50 of Sv was $6.534 \mu \mathrm{mol}$ while that of Aln was $30.56 \mu \mathrm{mol}$ (fig. 1).
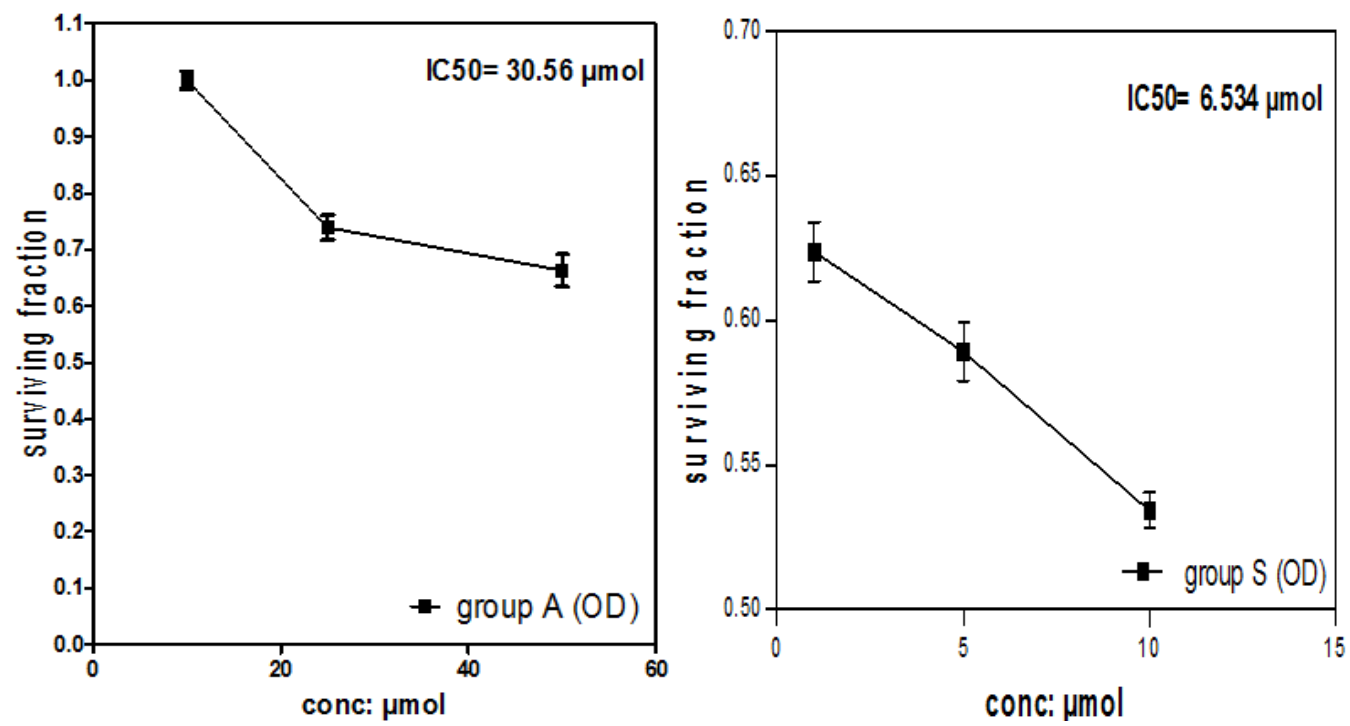

Fig. 1: IC 50 calculation of alendronate and simvastatin $(n=24)$ 


\section{Cytotoxicity assay results}

Cytotoxic effect was determined $48 \mathrm{~h}$ post treatment with Aln, Sv, $\mathrm{Aln}+\mathrm{Sv}$. In all groups, a decrease in the mean viability percentages of the treated Hep-2 cells in relation to control cells was observed in all groups (fig. 2). The mean viability in was lower than that group (S). The mean viability of the combined group $(A+S)$ was lower than group (A) or group (S) used alone. This means that combining both drugs showed the higher cytotoxic effect on HEP-2 cell line.

The combination of both agents exhibited a synergistic effect. Descriptive statistics analysis of the cytotoxicity assay comparing control group (CN) with the groups treated with Aln, Sv, Aln+Sv, revealed that there was a statistically significant difference between all groups and the control group which means that both Sv and Aln and combination of their IC 50 doses exhibited cytotoxic effect on Hep-2 cancer cells (P-values < 0.05). There was no significant difference in the cytotoxicity of Aln and Sv used alone suggesting that both groups have nearly the same cytotoxic effect on Hep-2 cells when used separately ( $\mathrm{p}$-values $>0.05$ ).

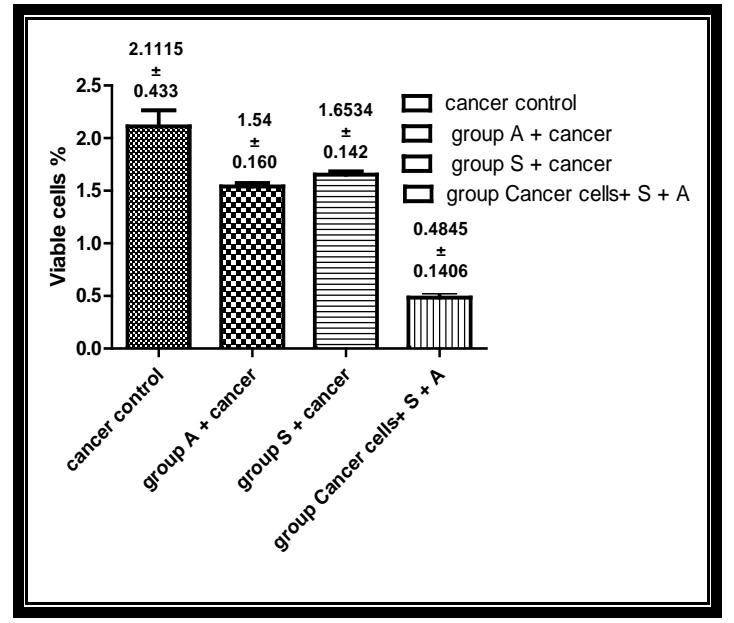

Fig. 2: Effect of simvastatin, alendronate and combination on cancer cell viability $\left(n=24, p^{* *}<0.0001\right.$, data given in mean $\left.\pm S D\right)$

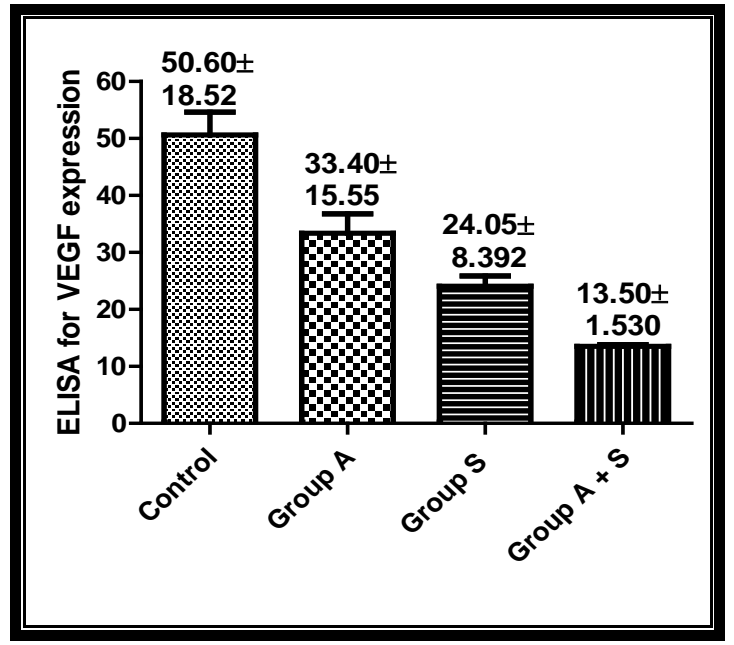

Fig. 3: Effect of simvastatin, alendronate and combination on vascular endothelial growth factor expression in cancer cells $\left(n=24, p^{* *}<0.0001\right.$, data given in mean $\left.\pm S D\right)$

\section{Elisa for VEGF results}

VEGF measures in all groups were significantly lower than the control group (P-values < 0.05). The mean of VEGF in the group $(\mathrm{S})$ was lower than that of the group (A). The mean of VEGF expression in the combined group $(A+S)$ was lower than each group separately (group S or group A) alone. There was a synergistic effect towards decreasing the VEGF expression in the combined group $(\mathrm{S}+\mathrm{A})$. Descriptive statistical analysis of cytotoxicity assay comparing control group (CN) with the groups treated with Aln, Sv, Aln+Sv, revealed that there was a statistically significant difference between all groups and the control group suggesting that both Sv and Aln and combination of both drugs at their IC 50 doses can lower the VEGF production by Hep-2 cancer cells (P-values < 0.05) (fig. 3). There was no statistically significant difference in VEGF expression between groups treated with Aln and Sv alone suggesting that both groups have nearly the same effect on Hep-2 VEGF expression when used separately (p-values $>0.05$ ).

\section{DISCUSSION}

In this study, we describe the differential response of OSCC cell line to the simultaneous targeting of HMG Co-A reductase and the farnesyl transferase pathways.

Aln and Sv are members of two families known to suppress enzymes in the mevalonate pathway. Aln is a farnesyl pyrophosphate synthase inhibitor and Sv is an HMG CoA reductase inhibitor. The combination of both drugs can effectively inhibit the mevalonate cascade and the generation of downstream isoprenoids and geranylgeranylation of proteins [23].

Bisphosphonates, which are potent inhibitors of bone resorption, have been recently used in bone diseases induced by cancer. The benefits of BPs in treating such diseases are mainly due to their antiosteoclastic properties. There is increasing evidence that BPs also directly inhibit cancer cells by acting either on tumour cell proliferation/survival or by having an anti-angiogenic potential [22]. Many in vitro studies have established the antiproliferative effects of pamidronate or Aln on different cancer cells, such as osteosarcoma, breast, myeloma, and melanoma and recently on neuroblastoma cancer cells [23].

In the present work, there was a decrease in the mean viability percentages of the treated Hep-2 cells in relation to control cells in all groups. The mean viability in the group (A) was lower than that of the group (S). There was no statistically significant difference in cytotoxicity of Aln and Sv used alone suggesting that both groups nearly have the same cytotoxic effect on Hep-2 cells when used separately.

According to Muller et al., Aln presented a desirable effect when treating angiogenesis exhibiting carcinoma [24]. They tested three nitrogen containing bisphosphonates and showed that Aln was the most powerful in inhibiting tumor growth of A431 human epidermoid carcinoma cells. Farese et al., indicated that alendronate with concentrations ranging from 10 to 1000 micro M. may play a role in inhibiting canine osteosarcoma tumor growth after $48 \mathrm{~h}$ culture in a dose dependent manner [25]. Menter et al., demonstrated the role of $\mathrm{Sv}$ in down-regulating tumor cell proliferation in prostate cancer cell lines [25]. In accordance, Min L. showed that Sv also inhibited the proliferation of colon cancer cell line in vitro in time-and dose-dependent manner. IC50 values of Sv determined at $96 \mathrm{~h}$ were 45.6 and $33.7 \mu \mathrm{Mol}$. Similarly, Wu et al., found that Sv suppressed human U251 and U87 glioma cell proliferation in a concentration of $10 \mu \mathrm{mol}$. Colonies sizes decreased after Sv treatment as compared to control, suggesting that Sv may repress the proliferation of glioma cell in vitro, when used at higher concentrations [27]. These effects may be due to retarded growth. The difference in the dose used may be attributed to the difference of cell line used and its sensitivity to the drug.

In the present research, the mean viability of the combined group $(A+S)$ was lower than group $(A)$ or group $(S)$ when used alone. This suggests that combining both drugs showed the higher cytotoxic effect on HEP 2 cell line. The combination of both agents exhibited a synergistic effect. Descriptive statistics of cytotoxicity assay demonstrated a statistical significance between all treated groups and the control group which suggested that both Sv and Aln and their combination of their Ic 50 doses exhibited a cytotoxic effect on Hep-2 cancer cells. 
VEGF a leading mediator of angiogenesis involved in the growth of almost all tumour [28]. Thus, anti-angiogenic therapy targeting the inhibition of VEGF production and/or its effects on endothelial cells is considered a very important step towards solid cancer treatment since preventing angiogenesis leads to cancer mass shrinkage and further regression.

Our research showed that VEGF measures in all groups were significantly lower than the control group. The mean of VEGF in S group is lower than the mean in the group (A). There was no statistically significant difference in VEGF expression of groups treated with Aln and Sv alone denoting that both groups have nearly the same effect on Hep-2 VEGF expression when used separately.

In accordance with previous studies [29] demonstrating the association of bisphosphonates with the antitumor and antiangiogenic effects, novel possibilities for this drug class are proposed.

In contrast to the data of our group demonstrating that VEGF production decreases by statin-treated cancer cells, Takenaka et al., demonstrated that Sv significantly stimulated VEGF to release in a dose-dependent manner in A10 rat vascular smooth muscle cells [30]. The stimulation was, however, visible, at high, micro molar concentrations of the drug. Also, in another recent study, Sv enhanced VEGF expression in hearts of apo E knockout mice, improving [31].

The mean of VEGF expression in the combined group $(A+S)$ was lower than in each group separately (group $S$ or group A) alone. There was a synergistic effect towards decreasing the VEGF expression in the combined group $(\mathrm{S}+\mathrm{A})$. Descriptive statistics analysis of cytotoxicity assay comparing control group with the groups treated with Aln, Sv, Aln+Sv, revealed a statistically significant difference between all groups and the control group suggesting that both Sv and Aln and the combination of both drugs at their IC 50 doses are capable of lowering the VEGF production of Hep-2 cancer cells.

In the current study, it was illustrated that a synergistic effect can be obtained from combining Sv with Aln. Combining both Aln and Sv significantly decreased cancer cell viability as well as angiogenesis in contrast to the results obtained when each drug acted separately.

In addition to their effects on the proliferative pathways, it is important to note that Statins are currently under intense research regarding their role in immunomodulation, proteasome inhibition and disruption of pathways associated with inflammation and angiogenesis validating their anti-neoplastic properties [32-40].

\section{CONCLUSION}

Further preclinical and clinical trials are mandatory to assess the effect of different members of these cholesterol controlling families and different doses in treating cancer of head and neck. A combination of $\mathrm{Sv}$ and an in their Ic50 doses demonstrate a dramatic effect on lowering the proliferation and VEGF expression of Hep-2 cancer cells cultured in vitro. However, it is recommended to further study the clinical relevance of these in vitro findings and apply it in vivo. Combining Aln and Sv could be indicated in the near future as an adjuvant to existing chemotherapeutic protocols.

\section{ACKNOWLEDGEMENT}

This work was supported by the National Research Centre, Egypt.

\section{AUTHOR CONTRIBUTION}

All authors have conceived and designed the experiment. Dr Dina Sabry has performed the ELISA testing. All authors have contributed in analysing the data and writing the paper.

\section{CONFLICTS OF INTERESTS}

\section{Declared none}

\section{REFERENCES}

1. Vishnu P, Srinivasa A. Evaluation of anticancer activity of tridax procumbus leaf extracts on A549 and Hep G2 cell lines. Asian J Pharma Clin Res 2015:129-32.
2. Mehrotra R, Yadav S. Oral squamous cell carcinoma: etiology, pathogenesis and prognostic value of genomic alterations. Ind J Canc 2006;43:60-6.

3. Parkin D, Bray F, Ferlay J, Pisani P. Global cancer statistics. Can Canc J Clin 2005;55:74-108.

4. Rousseau A, Badoual C. Head and Neck: Squamous cell carcinoma: an overview. Atlas Genet Cytogenet Haematol Oncol 2012;16:145-55.

5. Chan KK, Oza AM, Siu L. The statins as anticancer agents. Clin Cancer Res 2003;5:10-9.

6. Corcos L, Le Jossic-Corcos C. Statins: perspectives in cancer therapeutics. Dig Liver Dis 2013;45:795-802.

7. James Lo, Ulrich L. Pleiotropic effects of statins. Annu Rev Pharmacol Toxicol 2009;45:89-114.

8. Fritz G. Targeting the mevalonate pathway for improved anticancer therapy. Curr Cancer Drug Targets 2009;9:626-38.

9. Guise TA. Antitumor effects of bisphosphonates: promising preclinical evidence. Canc Treat Rev 2008;34 Suppl 1:S19-24.

10. Morgan G, Lipton A. Antitumor effects and anticancer applications of bisphosphonates. Semin Oncol 2010;37 Suppl 2:S30-40.

11. Gnant M, Clézardin P. Direct and indirect anticancer activity of bisphosphonates: a brief review of published literature. Cancer Treat Rev 2012;38:407-15.

12. Mackie P, Fisher J, Zhou H, Choong P. Bisphosphonates regulate cell growth and gene expression in the UMR 106-01 clonal rat osteosarcoma cell line. Br J Cancer 2001;84:951-8.

13. Sonnemann J, Eckervogt V, Truckenbrod B, Boos J, Winkelmann W, Van Valen F. The bisphosphonate pamidronate is a potent inhibitor of human osteosarcoma cell growth in vitro. 20 Anticancer Drugs 2001;12:459-65.

14. Fromigue O, Lagneaux L, Body J. Bisphosphonates induce breast cancer cell death in vitro. J Bone Miner Res 2001;15:2211-2.

15. Reinholz G, Getz B, Sanders E, Karpeisky M, Padyukova N, Mikhailov S. Distinct mechanisms of bisphosphonate action between osteoblasts and breast cancer cells: the identity of a potent new bisphosphonate analogue. Breast Cancer Res Treat 2002;71:257-68.

16. Lee M, Fong E, Singer F, Guenette R. Bisphosphonate treatment inhibits the growth of prostate cancer cells. Cancer Res 2001;61:2602-8.

17. Takahashi $R$, Shimazaki $C$, Inaba $T$, Okano $A$, Hatsuse $M$, Okamoto A. A newly developed bisphosphonate, YM529, is a potent apoptosis inducer of human myeloma cells. Leuk Res 2001;25:77-83.

18. Riebeling C, Forsea A, Raisova M, Orfanos C, Geilen C. The bisphosphonate pamidronate induces apoptosis in human melanoma cells in vitro. Br J Cancer 2002;87:366-71.

19. Vorotnjak M, Boos J, Lanvers-Kaminsky C. In vitro toxicity of bisphosphonates on human neuroblastoma cell lines. Anticancer Drugs 2004;15:795-802.

20. Mazieres J, Tillement V, Allal C, Clanet C, Bobin L, Chen Z Geranylgeranylated, but not farnesylated, RhoB suppresses ras transformation of NIH-3T3 cells. Exp Cell Res 2005;304:354-64.

21. Muller S, Migianu E, Lecouvey M, Kraemer M, Oudar 0 . Alendronate inhibits proliferation and invasion of human epidermoid carcinoma cells in vitro. Anticancer Res 2005;25:2655-60.

22. Farese JP, Ashton J, Milner R, Ambrose LL, Van Gilder J. The effect of the bisphosphonate alendronate on the viability of canine osteosarcoma cells in vitro. in Vitro Cell Dev Biol Anim 2004;40:113-7.

23. Menter D, Ramsauer V, Harirforoosh S, Chakraborty K, Yang P, Hsi L. Differential effects of pravastatin and simvastatin on the growth of tumor cells from different organ sites. PLoS One 2011;6:e28813.

24. Hongtau W, Hao J, Dunyue L, Ye X, Changsheng Q, Dong Z. Effect of simvastatin on glioma cell proliferation, migration and apoptosis. Neurosurg 2009;65:1087-97.

25. Xie K, Wei D, Shi Q, Huang S. Constitutive and inducible expression and regulation of vascular endothelial growth factor. Cytokine Growth Factor Rev 2004;15:297-324.

26. Green J. Bisphosphonates: a preclinical review. Oncology 2004;9:3-13. 
27. Takenaka M, Hirade $\mathrm{K}$, Tanabe $\mathrm{K}$, Akamatsu S, Dohi S, Matsuno H. Simvastatin stimulates VEGF release via p44/p42 MAP kinase in vascular smooth muscle cells. Biochem Biophys Res Commun 2005;301:198-203.

28. Siddiqui A, Gustafsson $\mathrm{T}$, Fischer $\mathrm{H}$, Widegren $\mathrm{U}$, Hao $\mathrm{X}$ Mansson-Broberg A. Simvastatin enhances myocardial angiogenesis induced by vascular endothelial growth factor gene transfer. J Mol Cell Cardiol 2004;37:1235-44.

29. Youssef S, Stuve O, Patarroyo J, Ruiz P, Radosevich J, Hur E. The HMG-CoA reductase inhibitor, atorvastatin, promotes a Th2 bias and reverses paralysis in central nervous system autoimmune disease. Nature 2002;420:78-84.

30. Hilgendorff A, Muth H, Parviz B, Staubitz A, Haberbosch W, Tillmanns H. Statins differ in their ability to block NF-kappa B activation in human blood monocytes. Int J Clin Pharma Ther 2003;41:397-401.

31. Tilkin-Mariame A, Cormary C, Ferro N, Sarrabayrouse G, LajoieMazenc I, et al. Geranylgeranyl transferase inhibition stimulates anti-melanoma immune response through MHC class I and costimulatory molecule expression. J FASEB 2005;19:1513-5.

32. Rao S, Porter DC, Chen X, Herliczek T, Lowe M, Keyomarsi K Lovastatin-mediated G1 arrest is through inhibition of the proteasome, independent of hydroxymethyl glutaryl-CoA reductase. Proc Natl Acad Sci U S A 1999;96:7797-802.

33. Veillard NR, Mach F. Statins: the new aspirin? Cell Mol Life Sci 2002;59:1771-86.

34. Weis M, Heeschen C, Glassford A, Cooke J. Statins have biphasic effects on angiogenesis. Circulation 2002;105:739-45.

35. Shibata M, Ito Y, Morimoto J, Otsuki Y. Lovastatin inhibits tumor growth and lung metastasis in mouse mammary carcinoma model: a p53-independent mitochondrial-mediated apoptotic mechanism. Carcinogenesis 2005;25:1887-98.

36. Macaulay R, Wang W, Dimitroulakos J, Becker L, Yeger H. Lovastatin-induced apoptosis of human medulloblastoma cell lines in vitro. J Neuro-Onc 1999;42:1-11.

37. Alarmal M, Ravi S. In vitro cytotoxicity of trichodesma indium extracts against three human cancer cell lines. Asian J Pharma Clin Res 2014;7:103-5.

\section{How to cite this article}

- Dina Sabry Abd-El-Fattah, Marwa Mohammed Ellithy, Riham Mohammed Aly. Synergistic cytotoxic effect of statins and bisphosphonates on squamous cell carcinoma cell line. Int J Pharm Pharm Sci 2017;9(8): 123-127 